\title{
Vivência e prática educativa: a relação afeto-intelecto mediando modos de ser professor e aluno
}

\author{
Emotional experience and educational practice: the affection and \\ intellectual relation mediating forms of being teachers and students
}

\author{
Eliana de Sousa Alencar Marques ${ }^{1}$ \\ Maria Vilani Cosme de Carvalho ${ }^{2}$
}

\begin{abstract}
RESUMO
Este artigo discute dados de pesquisa bibliográfica e empírica com o objetivo de analisar a categoria vivência e sua relação com as práticas educativas escolares. Essa discussão, fundamentada nas ideias de Vigotski (2017, 2009, 2004, 2000, 1991), Espinosa (2008, 2007) e comentadores permite a compreensão de que o desenvolvimento da consciência é processo, ao mesmo tempo, racional e afetivo, ligado à vida real das pessoas, ou seja, à dialética objetividade e subjetividade que expressa e determina a existência humana. Os dados da pesquisa empírica envolvem um professor de educação básica na área de matemática e quatro alunos. Na produção de dados foram utilizados memoriais e entrevista reflexiva. Núcleos de Significação foi o procedimento de análise. Os resultados apontam que, mediados pelo social, professores e alunos produzem afetos que orientam a produção de novos sentidos sobre ser professor e ser aluno na escola e alteram a relação com a atividade escolar. A mudança dos estados afetivos gera transformações que comprovam existência de algo novo, algo particular e peculiar que modifica a relação social, e que é, segundo Vigotski, o principal indicativo da existência de perejivânia (vivências).
\end{abstract}

Palavras-chave: Perejivânie. Prática educativa. Relação afeto e intelecto. Subjetividade e objetividade.

\begin{abstract}
This article discusses bibliographical and empirical data aiming to analyze the category Perezhivanie and its relation with the school educational activities. This discussion is based on the ideas of Vygotsky (2017, 2009, 2004, 2000, 1991), Espinosa (2008, 2007) and scholars. It helps with the comprehension that the development of the counsciousness is a process, at the same time, rational and affective linked to the real life of people, in other words, to the dialectics of objectivity and subjectivity. Such dialectics expresses as well as determines the human existence. The empirical research involves a basic education teacher in the field of mathematics and four students. For data collection, we used reflexive and memorialistic interviews, that we analyzed with the method of nuclei of meanings. The results indicate that, mediated by social environment, teachers and students produce affection which guide the production of new meanings concerning the identity of teachers and students at school by changing the relation with the school activity. The change of the affective states results in changes that prove the existence of something new, something particular and peculiar that changes the social relation, that is, according to Vygotsky, the main trace of the existence of perezhivanie.
\end{abstract}

Keywords: Perezhivanie. Educational practice. Affect and intellect relation. Subjectivity and Objectivity.

\footnotetext{
1 Professora do Programa de Pós-Graduação em Educação da Universidade Federal do Piauí-

Brasil. esalencar123@ufpi.edu.br

${ }^{2}$ Professora do Programa de Pós-Graduação em Educação da Universidade Federal do Piauí -

Brasil.vilacosme@ufpi.edu.br
} 


\section{Introdução}

O atual sistema escolar brasileiro, especialmente a rede pública de ensino, coloca aos educadores e às educadoras o desafio de desenvolver práticas educativas que, em tese, possam garantir formação humana aos alunos. Dizemos "em tese" porque nem sempre os educadores e as educadoras, em nosso país, dispõem de condições para realizar esse projeto educacional, sobretudo em uma sociedade capitalista como a nossa, em que a educação escolarizada tende a reproduzir relações de opressão e de dominação que potencializam processos de desumanização.

Isso acontece porque a educação escolarizada assume diferentes forma e conteúdo, conforme são os interesses que movem a sociedade no intuito de integrar os membros a um determinado modo de organização da vida social historicamente datada. A educação constitui-se, assim, em processo pelo qual a sociedade se reproduz a si mesma ao longo de seu movimento histórico.

Diante disso, cabe questionar: que educação queremos para as novas gerações? O que é importante reproduzir nessa sociedade que mereça o esforço de educadores e educadoras? Que humano queremos formar?

A partir do que afirma Saviani (1997), sobre os seres humanos não nascerem humanos, mas aprenderem a sê-lo a partir do momento que são educados para isso, compreendemos e defendemos que a educação para a formação humana é o tipo de projeto educativo que favorece a construção dessa humanidade.

Por isso, Vigotski (1998, 2010, 2018) considera que o ensino só cumpre seu papel de produzir humanidade no homem quando favorece o desenvolvimento de algo novo, a formação de qualidades que colocam os seres humanos em condição qualitativamente diferente dos outros animais. Para esse teórico, educar significa a possibilidade de formar algo novo no educando.

$\mathrm{Na}$ explicação de como se constitui esse processo, Vigotski (2004, 2010) desenvolve a tese de que o psiquismo humano tem sua gênese na relação significada com o social - o ser humano desenvolve a consciência à medida que produz significados e sentidos. Os significados possibilitam nossa comunicação e 
nossa imersão na história, porque "são generalizações, conceitos que são partilhados, construídos e reconstruídos historicamente pelos homens que dividem a mesma cultura"; já os sentidos medeiam nossa relação afetiva com o mundo, "são, assim, determinados pelo conjunto de momentos afetivo-volitivos existentes em nossa consciência”, resultado do modo como compreendemos e sentimos as coisas, resultado da relação afeto-intelecto (MARQUES; CARVALHO, 2017, p. 5).

Vigotski inspira-se em Espinosa e provoca uma revolução na Psicologia, vez que muda a ontologia do fenômeno afetivo e altera nossa compreensão acerca do desenvolvimento das atividades humanas, dentre elas, os processos educativos que passam a ser analisados não mais sob a égide da razão, mas da relação afeto e intelecto.

Para explicar esse processo, Vigotski desenvolve a categoria perejivânie. De acordo com o autor (2018), perejivânia (vivências) ${ }^{3}$ expressam a unidade da relação entre a consciência e o meio, da relação interior de dada pessoa com um acontecimento externo, fruto daquilo que se vive nas relações sociais, isto é, vivência é a unidade que explica não apenas o modo como nos apropriamos do mundo, mas também que conhecimentos construímos das relações com o meio e a potência dos afetos nessa relação (MARQUES, 2014).

Do ponto de vista dos processos educativos, tal formulação tem estimulado pesquisadores e educadores a questionarem: é possível potencializar a relação afeto e intelecto no sentido de colaborar com o pleno desenvolvimento de nossos alunos na escola? O que cabe a professores e alunos nesse processo? Como investigar essa relação e, assim, construir conhecimentos que favoreçam processos educativos mais potentes para produzir aprendizagem e desenvolvimento nas escolas?

$\mathrm{Na}$ produção de conhecimentos que fundamentassem discussão sobre essas questões, discutimos, neste artigo, dados de pesquisa bibliográfica e empírica com o objetivo de analisar a categoria vivência e sua relação com as práticas educativas escolares. Essa discussão tem sua gênese na tese de doutoramento de Marques (2014) e está fundamentada nas ideias de Vigotski (1998, 2000, 2004, 2009, 2018),

\footnotetext{
${ }^{3}$ Em muitas traduções das obras de Vigotski, aparece o termo "vivência”. Por essa razão, optamos por fazer uso do termo vivência no restante do artigo.
} 
Espinosa (2007, 2008) e apropriadores, que colaboraram na compreensão de que o desenvolvimento da consciência é processo, ao mesmo tempo, racional e afetivo, ligado à vida real das pessoas, ou seja, à dialética objetividade e subjetividade que expressa e determina a existência humana. Para tanto, a discussão no artigo está organizada em três partes mais as considerações finais.

$\mathrm{Na}$ primeira parte do artigo, discorremos sobre o trabalho de Vigotski para criar uma nova psicologia que se dedicasse à compreensão da constituição do humano concreto; discutimos as ideias de Espinosa (2007, 2008), que convergem para a compreensão das elaborações de Vigotski acerca da categoria vivência. Em seguida, na segunda parte, apresentamos informações metodológicas sobre a pesquisa realizada em nível de doutoramento, na qual se fez uso da categoria vivência para analisar os dados empíricos. Na terceira parte, exploramos um recorte da referida pesquisa, com o objetivo de analisar o processo de constituição de professores e alunos envolvidos com práticas educativas consideradas bemsucedidas na escola.

Finalizamos com questões que apontam vivência na Psicologia Histórico Cultural como categoria com grande valor heurístico para pesquisas em Educação que objetivem analisar professores e alunos em processo de desenvolvimento, além de colaborar com a produção de conhecimentos essenciais para mediar o planejamento e o desenvolvimento de práticas educativas com potencial humanizador.

\section{Perejivânie e o desenvolvimento da atividade humana: considerações com base}

\section{em Vigotski e Espinosa}

Em Teoria e método em psicologia, Vigotski (2004, p. 56) anuncia que a psicologia, mesmo tendo diante de si “[...] a imensa tarefa de estudar a totalidade do comportamento humano [...]" ignorou esse problema, “[...] fechando para si mesma o caminho da investigação de problemas mais ou menos complexos do comportamento humano". O problema apontado por Vigotski dizia respeito ao fato de que nenhuma das principais tendências vigentes, na sua época, buscava explicações para a especificidade do humano, tomando como referência a própria 
condição humana, ou seja, "[...] o humano estava sendo visto sempre, de um modo ou de outro, como determinado por leis físicas e biológicas estreitas, ou por leis transcendentais ou metafísicas inapreensíveis [...].” (DELARI JUNIOR, 2013, p. $56)$.

Até esse momento, a Psicologia ainda não havia produzido condições de apresentar uma explicação para a constituição do humano pautada naquilo que lhe era mais específico, o desenvolvimento histórico da sua consciência. Faltava-lhe, nas palavras de Delari Junior (2013), ser radical, voltar-se para o homem real e concreto. O caminho encontrado por Vigotski para superar a crise na qual se encontrava a Psicologia da sua época foi propor a psicologia humana, a psicologia do homem concreto:

$\mathrm{Na}$ busca de diferenciação com relação às abordagens convencionais, e de proposição de uma psicologia humana, como ciência que trata daquilo que é especificamente humano, é significativo o princípio filosófico (presente em Hegel) de que se a essência do animal realiza-se no seu ser, a essência humana realizase no seu tornar-se. O homem só pode definir-se como tal no movimento de tornar-se humano, não se define por uma essência transcendental, mas torna-se aquilo que é na medida em que só pode ser aquilo em que se torna (DELARI JUNIOR, 2013, p. 57).

Tomando para si o problema da consciência humana como aquele que abriria as portas para sua nova psicologia, Vigotski (1998, 2004, 2009, 2018) constrói argumentos para explicar que, na relação com o meio, na produção da vida real, o ser humano se relaciona com situações sociais que medeiam a formação de sua consciência.

A consciência humana, segundo Vigotski (idem), desenvolve-se tardiamente, porém, isso não significa, de modo algum, que a consciência tem menor valor no processo de desenvolvimento humano ou um produto de menor valor ontológico, mas que sobre essa base atesta a possibilidade de intervenção do humano na realidade a fim de transformá-la. Isso confirma o pressuposto de que toda possibilidade pode vir a ser realidade, desde que haja humanos em condição para isso, capazes de produzir condições objetivas e subjetivas sem as quais nenhuma 
transformação é possível. Uma condição subjetiva necessária para isso é o desenvolvimento da atividade consciente.

Os significados e os sentidos são alicerces para o desenvolvimento da atividade consciente. De acordo com Marques e Carvalho (2017), o significado da palavra é, ao mesmo tempo, fenômeno do pensamento e do discurso, o que representa a unidade da palavra com o pensamento. No campo semântico, corresponde às relações que a palavra encerra. No campo psicológico, são generalizações, conceitos que são partilhados, construídos e reconstruídos historicamente pelos homens que dividem a mesma cultura. Em outras palavras, é o que possibilita a comunicação entre os homens, logo, são imprescindíveis às atividades humanas.

O significado é, ao mesmo tempo, linguagem e pensamento, porque é unidade do pensamento verbalizado. Já os sentidos, embora também sejam produzidos historicamente, porque têm a mediação do social, revelam construções pessoais ligadas aos aspectos afetivos. São, assim, determinados pelo conjunto de momentos afetivo-volitivos existentes em nossa consciência; destarte, são mais amplos que os significados e expressam, segundo Vigotski (2009), a soma de todos os fatos psicológicos que nos marcam e nos mobilizam positiva ou negativamente.

A relação que estabelecemos com o mundo social é sempre mediada pela produção de significados e sentidos. É a relação de significação (significados e sentidos) que particulariza a situação social, produzindo alteração da nossa relação com o mundo e, por isso, altera nossa consciência sobre as coisas, as pessoas, os processos, enfim, que nos transforma. E o que há de particular nessas situações que, ao serem significadas, podem gerar desenvolvimento da consciência?

O particular, o específico que ocorre em determinadas situações sociais que as tornam potencialmente transformadoras da consciência humana é o fato de elas constituírem vivências. E o que vem a ser vivência?

Para alguns estudiosos dessa categoria, como Toassa (2011), Toassa e Souza (2011), Prestes (2011) e Delari Junior (2009), perejivânie (vivência) é termo russo que encontra relação com o substantivo alemão Erlebnis aproximando-se de viver, presenciar, experimentar, sofrer, suportar, aguentar. Perejivânie é uma palavra russa derivada do par de verbos perejit e perejivát, originários do verbo jit (viver). 
De acordo com esses estudiosos, os verbos russos se agrupam em pares de significados praticamente idênticos, diferenciando-se pelo seu aspecto perfectivo e imperfectivo. Esclarecem que o verbo perjivát e o substantivo perejivânie indicam, por conseguinte, vivência de conteúdo de finalização incerta, seja sua ocorrência habitual ou não. A inconclusão é, assim, um aspecto ineliminável desses vocábulos. Isso evidencia que perejivânie (vivência) significa movimento, situação processual, dinâmica, é situação que tem início e pode ou não ter um fim, pode ir e vir.

Situações sociais que desencadeiam vivências implicam emoções fortes, que alteram a relação que temos com as coisas, com as pessoas, com os processos, enfim, com a realidade, pois, significa que os afetos produzidos nessa relação formam e/ou transformam nossos sentidos. Compreendemos, portanto, que não são situações pelas quais transitamos de modo indiferente; longe disso, elas "[...] envolvem necessariamente qualidades emocionais, sensações e percepções, acarretando uma imersão do sujeito" (TOASSA, 2011, p. 34/35).

Marques e Carvalho (2017, p. 7) esclarecem que Vigotski faz uso dessa categoria para sustentar a tese de que:

A relação do homem com o mundo e com os outros é sempre uma relação afetiva produtora de sentido. Os sentidos são produzidos em virtude dos afetos constituídos nas vivências de cada ser humano. Entendemos com isso que são os afetos que colocam os indivíduos em situação de atividade ou de passividade, porque são os afetos que determinam a qualidade do sentido produzido pelo indivíduo na relação com a realidade.

Produzir vivências significa sempre implicação emocional, significa algo forte, acabado e inacabado, porém, não se revela na relação imediata do ser humano com o meio, no comportamento visível da pessoa, mas, no significado dessa relação. Afinal, “[...] a vivência sempre denota o modo como a criança toma consciência e concebe, de como ela se relaciona afetivamente para com certo acontecimento" (VIGOTSKI, 2011, p. 686). Disso podemos reiterar que vivência pressupõe sempre a objetivação da relação afeto e intelecto na constituição da consciência humana. 
Para Vigotski (2011), no processo de desenvolvimento da consciência humana, a situação social (aquilo que se vive) e as especificidades do ser humano (criança, adolescente, jovem, adulto) formam uma unidade de contrários. Desse modo, vivência não diz respeito meramente à particularidade da pessoa ou à particularidade do meio social, mas indica a síntese da relação entre a pessoa e o meio social (no caso aqui não o meio em absoluto, mas as significações sobre a situação social). Assim, toda vivência é mediada pelo processo de significação, em outras palavras, pela produção de significados e sentidos sobre o que se vive e como se vive, pelo modo como essa situação afeta quem dela participa.

Ainda sobre o meio, convém esclarecer, com Vigotski (2011, 2018), que o seu papel no desenvolvimento pode ser evidenciado pela relação criança e meio:

\begin{abstract}
Duas ideias nos permitem defender esse pensamento. A primeira que o papel de quaisquer elementos do meio é distinto em diferentes degraus etários. Por exemplo: a fala das pessoas que estão ao redor da criança pode ser a mesma quando ela tem seis meses, um ano e seis meses ou três anos e seis meses. Ou seja, a quantidade de palavras que ela ouve e o caráter da fala, do vocabulário, da erudição, considerando o contexto cultural, podem permanecer os mesmos. Contudo, qualquer um entende que esse fator, que não mudou ao longo do desenvolvimento, tem um significado diferente quando a criança compreende a fala, quando não a compreende de forma alguma e quando se encontra entre essas duas fases, começando a compreendê-la. (VIGOTSKI, 2018, p. 74).
\end{abstract}

Em vista disso, é necessário entender que, ao fazer referência ao meio, Vigotski não está se referindo a um lugar físico, mas, sim, à relação que a criança estabelece com a realidade, relação sempre mediada pela significação. Quanto mais a relação com o meio se complexifica, mais qualidades humanas essa criança conquista no curso do seu desenvolvimento. Não é à toa que Vigotski, ao fazer referência ao meio no processo de desenvolvimento da criança, considera-o não como condição, mas como fonte de desenvolvimento, isto é, de oportunidades, de relações que podem mudar o curso do desenvolvimento humano.

Vivência é a categoria que vincula objetivamente a teoria de Vigotski ao Materialismo Histórico Dialético, porque ela nos permite compreender como o ser humano, na relação com a realidade concreta, torna-se quem é. Para esse teórico, 
a consciência do ser humano que se manifesta naquilo que ele é, isto é, naquilo que ele sente, naquilo que ele pensa, no modo como ele age, encontra sua ontologia primária na relação com o meio e na subjetivação dessa relação. Assim, vivência é a categoria que melhor explica a dialética objetividade e subjetividade na psicologia de Vigotski.

Compreendemos, ainda, que vivência é a categoria que ilustra, de forma mais objetiva possível, a lei geral do desenvolvimento anunciada por Vigotski (1998, 2011). De acordo com essa lei, toda forma superior de comportamento aparece em cena duas vezes durante seu desenvolvimento. Primeiro, como forma coletiva, no social, manifestada nas relações com os outros, depois, como manifestação do comportamento individual, subjetivado no social. Se toda vivência implica desenvolvimento, essa categoria é chave para a compreensão do conteúdo desenvolvimentista da psicologia vigotskiana, pois ela integra o processo de internalização das funções psíquicas superiores.

Situando essa discussão no campo das pesquisas que são desenvolvidas tendo como objeto de investigação a educação, a formação de educadores e as práticas educativas, vivência se apresenta como dispositivo lógico capaz de revelar aspectos constitutivos da dimensão subjetiva da realidade educacional, sobretudo se essas pesquisas partem da visão monista de Vigotski (2000, 2004, 2009, 2011) acerca do humano como síntese das relações corpo-mente, afeto-intelecto, homemsociedade.

Todavia, a análise que se propõe a desvelar aspectos da dimensão subjetiva da realidade humana não tem pretensão de ser simples, mas complexa, dada a complexidade do humano. Esta, aqui referida, não pode ser interpretada como dificuldade, mas como ponto de partida para o entendimento do humano como "unidade na diversidade" (MARX, 2011, p. 68), síntese concreta das relações que estabelece com o real, logo, das mediações que o constituem.

Para melhor situar a prática educativa nesse contexto, consideramos importante recuperar a questão levantada anteriormente: é possível potencializar a relação afeto e intelecto no sentido de colaborar com o pleno desenvolvimento de nossos alunos na escola? 
Vivência abrange tanto o modo como um evento é emocionalmente vivido, quanto a forma como esse evento é cognitivamente entendido pela pessoa que a vive. Isso quer dizer que todas as práticas educativas são vivenciadas pelos alunos tanto no plano emocional, como no plano intelectual. Os sentidos produzidos sobre o que se vive na sala de aula resultam do modo como essas práticas afetam os alunos cognitivamente e afetivamente. Sobre isso, Vigotski (2010) esclarece que se quisermos suscitar nos alunos formas de comportamento mais desenvolvidas, teremos que nos preocupar em deixar nesses alunos vestígios emocionais potentes, porque a aprendizagem, segundo o bielo-russo, não se produz apenas pelo que se sabe, mas, sobretudo, pelo que se vive e se sente, enfim, pelo modo como afeta e é afetado pela situação educativa.

O modo como somos afetados pela realidade é o que nos leva a produzir ideias sobre as coisas. Essas ideias, segundo Espinosa (2007), podem ser adequadas ou inadequadas. A produção de ideias inadequadas é fruto das afecções que sofremos em nossa relação imediata com o mundo aparente, um conhecimento com base nisso é chamado por Espinosa de confuso ou inadequado. Ele ordena-o à "[...] imagination porque contêm, através das afecções do corpo, só imagens das coisas que afetam o corpo, imagens que não reproduzem o que essas coisas são em si” (BARTUSCHAT, 2010, p. 69).

Como eventos puramente corporais, fruto de nossas experiências com a realidade imediata, esse tipo de conhecimento não favorece nosso desenvolvimento, porque não provém da nossa reflexão consciente, crítica sobre as coisas, mas, sim, da agitação que provoca em nosso espírito. Por essa razão, Espinosa (2007) adverte que todo nosso entendimento deve se voltar para compreendermos as coisas sem erro e da melhor maneira possível. Para o filósofo, o fim de todas as ciências deve ser ajudar à "suprema perfeição humana", bem como devemos considerar inútil todo conhecimento que não favoreça isso, afinal, "[...] todas as nossas ações e ao mesmo tempo todos os nossos pensamentos devem ser dirigidos para esse fim" (ESPINOSA, 2007, p. 27).

Em relação às ideias adequadas, estas provêm do conhecimento que se produz de uma operação intelectual, na qual a mente humana deduz ideias de suas causas verdadeiras e não do seu encontro fortuito com as coisas ou do próprio acaso. 
Espinosa (2007, p. 33) considera que somente essas ideias alteram positivamente nossa potência, "[...] a partir do simples ouvir dizer, sempre que não tiver sido precedido pelo próprio entendimento, jamais alguém poderá ser afetado”.

De acordo com Bartuschat (2010), isso acontece porque, enquanto as ideias inadequadas nos determinam externamente, pois apenas reagimos ao que nos afeta, as ideias adequadas nos determinam internamente, mobilizam-nos a refletir, pensar, criticar, contemplar simultaneamente várias coisas, a interligar as semelhanças, as diferenças e as oposições delas. Nesse sentido, somos instigados à ação, saímos da condição de passividade, de confusão, de pura reatividade.

Conforme Marques e Carvalho (2014), a ação pressupõe o aumento de potência. Isso pode ser constatado na escola quando professores e alunos passam a demonstrar clareza dos motivos que orientam suas ações, quando produzem sentido consciente ao que fazem, quando demonstram clareza do que os afetam.

Entretanto, não podemos ignorar que professores e alunos sofrem as determinações do que acontece na sociedade em termos políticos e econômicos. A realidade social afeta diretamente a escola quando as políticas econômicas e educacionais colaboram para precarizar ainda mais o trabalho docente, quando as reformas curriculares contribuem para comprometer ainda mais a formação do aluno de baixa renda. A realidade objetiva afeta negativamente professores e alunos, que passam a produzir ideias inadequadas, confusas, mutiladas sobre os processos educativos, sobre a escola, sobre a profissão, porque, distraídos pela confusão que seus corpos sofrem, não conseguem compreender as verdadeiras causas que estão na gênese dessa realidade.

É a isso que Espinosa (2008) se refere quando afirma que nossa mente padece. O autor une dois termos historicamente separados, afeto e razão, identificando a potência de agir com a potência de compreender, ou seja, quanto mais consciência e clareza temos das coisas, dos processos, dos nexos que explicam a realidade histórica, mais nos sentimos mobilizados para a ação. Por outro lado, quanto menos compreendemos, menos agimos, mais vulneráveis ficamos, mais diminui sua potência. É por isso que Vigotski (2010, p. 139) se apoia em Espinosa ao afirmar: "[...] toda emoção é um chamamento a ação ou uma renúncia a ela." 
Marques e Carvalho (2014) consideram que a ideia espinosana de que o pensamento é sempre afetivo e se constitui na relação do homem com a realidade - no sentido de que o modo como significamos a realidade (produzimos ideias adequadas ou inadequadas) passa pela nossa compreensão intelectual e pelos nossos afetos, é a proposição que vai dar sustentação à tese de Vigotski de que, na relação com o meio, passamos por situações sociais que alteram nossa compreensão das coisas, transformam o sentido de nossas ações.

Isso acontece sempre que os significados e os sentidos que medeiam nossa relação com o meio se transformam, sinal de que a afetação constituída na situação social vivida leva à produção de vivências. São elas que sinalizam para a transformação da relação de sentido que temos com a realidade. E quais as implicações disso na prática educativa escolar?

Vivências remetem às transformações que alteram o modo de agir, pensar e sentir das pessoas. Na escola, os professores buscam, com suas práticas pedagógicas, produzir transformações positivas em seus alunos, fazê-los aprender, motivá-los a quererem alcançar o máximo de suas potências, torná-los melhores naquilo que se dispõem a fazer. Nesse sentido, refletir sobre as condições que precisam ser criadas a fim de constituirmos práticas educativas que favoreçam essas transformações é sempre meta a ser perseguida por todos os professores que, diariamente, se encontram com seus alunos.

Espinosa (2008) explica-nos que a potência de agir humana é da ordem do encontro, pois se relaciona com as infinitas possibilidades de composição entre os afetos nos encontros ativos (ações) e passivos (paixões), ou seja, relaciona-se com a nossa capacidade de afetar e ser afetado. Assim, os encontros na sala de aula, na escola, representam infinitas possibilidades e devem ser promovidos visando criar situações que possam favorecer a produção de ideias adequadas sobre a realidade.

Estimular o debate; a reflexão; o confronto de ideias; as interações coletivas; a discussão crítica; as aulas interativas; o acesso a fontes de informação diversificadas; acesso à tecnologia; a promoção de avaliações diferenciadas; o estímulo ao esporte, à cultura e a todas as manifestações artísticas, enfim, fazer da sala de aula um lugar de encontros em que seja possível aos estudantes desenvolverem ao máximo suas potencialidades intelectuais, criativas, afetivas, 
mas, sobretudo, que favoreça a compreensão verdadeira de como se produz a realidade social, dos desafios que uma sociedade como a nossa precisa enfrentar para alcançar o mínimo de justiça social.

Esse compromisso ético requer a significação da prática educativa por parte dos professores como situação social que nos afeta a todos e que, por essa razão, precisa potencializar vivências que elevem nossa capacidade de pensar, sentir e agir. Para ilustrar situações concretas que apontem nessa direção, daremos continuidade à discussão, recorrendo a alguns dos resultados da pesquisa empírica que envolveu professores e alunos de educação básica que têm conseguido realizar práticas educativas potencialmente transformadoras.

\section{Informações sobre a pesquisa}

A pesquisa a qual nos referimos neste artigo, envolveu um professor de matemática e quatro ex-alunos dele. Esses participantes foram escolhidos por serem reconhecidamente (em âmbito nacional e internacional) protagonistas de histórias bem-sucedidas em educação ${ }^{4}$. A pesquisa, de natureza qualitativa, foi realizada em dois momentos, no primeiro momento, com o professor, por meio de entrevista semiestruturada e do tipo reflexiva. No segundo momento, reunimo-nos com os alunos e propusemos a escrita do memorial. Neste relato, utilizaremos os dados relativos às entrevistas realizadas com o professor. $\mathrm{O}$ procedimento de análise é a proposta dos "Núcleos de Significação", porque permite apreender as mediações sociais constitutivas dos indivíduos em atividade, por meio de significações expressas nos discursos. Nesse procedimento, partimos da apreensão dos significados para chegar às "[...] zonas mais instáveis, fluidas e profundas, ou seja, as zonas de sentido" (AGUIAR; OZELLA, 2013, p. 304).

\footnotetext{
${ }^{4}$ A história de sucesso do professor e dos alunos vem sendo divulgada amplamente pela mídia local e nacional, desde 2011. A divulgação mais recente foi veiculada em reportagem do "Fantástico", da Rede Globo, exibido em 16/03/2014, como parte da série Educação.com. Para mais detalhes, consultar o link http://g1.globo.com/fantastico/noticia/2014/03/escola-publica-de-cidade-do-piauitem-alunos-motivados-e-otimos-resultados.html.
} 
Os significados expressos nas narrativas do professor revelam o que está na aparência, no discurso, mas o que nos interessa é o que está no subtexto, aquilo que não se mostra sem uma análise cuidadosa e profunda, ou seja, as mediações que, historicamente, explicam o que o singulariza. Por meio desse procedimento analítico, chegamos à identificação de três núcleos de significação: 1) O social mediando a escolha pela profissão, pelo curso de matemática e a identificação com a docência; 2) A dialética das dimensões objetivas e subjetivas da realidade mediando modos de ser professor; 3) A educação escolar, a responsabilidade do professor e o processo ensino e aprendizagem mediando o desenvolvimento da prática educativa bem sucedida. Esses três núcleos constituídos nas análises expressaram, dentre outras particularidades, os motivos, as escolhas, os percursos históricos, as vivências, as relações decisivas para o desenvolvimento desse professor. Cada núcleo de significação é constituído de indicadores que sintetizam aspectos de suas histórias de vida pessoal e profissional que indicam quais as mediações mais significativas na constituição da sua subjetividade.

Para nós, os núcleos de significação que organizamos constituem o que melhor expressa a singularidade do professor, que foi identificado na pesquisa por Torricelli. E, por serem representativos das mediações constitutivas desse professor, sobretudo em momentos históricos diferentes da sua trajetória de vida, em seus percursos históricos, esses núcleos foram nomeados considerando essas mediações. Em função do pouco espaço que um artigo dessa natureza comporta, serão exploradas as análises de apenas um dos núcleos de significação: "A educação escolar, a responsabilidade do professor e o processo ensino e aprendizagem mediando o desenvolvimento da prática educativa bem-sucedida.” Deste núcleo, analisamos o seguinte indicador: "Ideias adequadas sobre o processo ensino e aprendizagem”.

\section{Prática educativa escolar bem-sucedida mediada por vivências}

As análises partem dos significados e sentidos produzidos pelo professor sobre a prática educativa que realiza na escola. É importante ressaltar que essas significações são mediadas pelas condições de trabalho, pelas relações com os 
alunos e as alunas e com os pares, pelas suas crenças pessoais sobre qual a função da escola na sociedade, pelos seus valores, expectativas, etc.

Essas análises têm como objetivo apreender os afetos mobilizados nessas relações e as vivências produzidas nessas situações e que alteram a vida do professor. Iniciamos procurando apreender como Torricelli significa o trabalho que realiza na escola, para isso, destacamos três trechos da entrevista que consideramos bastante significativos:

[...] Quando eu paro muito para pensar eu não acho que eu fiz coisas extraordinárias, não.... Também não tive sorte, né! Eu fiz alguma coisa... Não sei se isso teria acontecido em outro lugar... Eu devo muito isso ao clima daqui, à cultura daqui, ao lugar que isso aconteceu [...]. (segunda entrevista).

[...] Eu fui um professor que tinha um trabalho, que tinha minha cargahorária, e eu procurei dar minha carga-horária, mas... Eu não fui aquele cara que foi sempre à risca... Eu não sou exemplo de professor, não sou exemplo de profissional... De uma pessoa que dá todo seu horário, ou que dá mesmo até todo o conteúdo, que faz tudo direitinho... Que faz todas as suas provas, entrega no dia certo... Não se atrasa... Eu não sou exemplo de profissional assim [...]. (segunda entrevista).

[...] Mas, por outro lado, eu digo o seguinte: eu quis muito que houvesse uma mudança no ensino de Matemática daqui... Isso foi uma coisa que eu quis... Como assim? Numa questão de valor... De se dar valor ao ensino da Matemática. Matemática não se estuda... Não é por acaso... Tem que ter sentido... Tem que ter os porquês... Então, eu não fui aquele professor, em momento nenhum, do tipo "eu vou lá para dar o conteúdo que está no livro didático e aquilo para quê? Ah! É porque o aluno tem que passar por aquilo e acabou", não... Eu sempre insisti que aquilo tinha que ter um valor, um valor... Eu insisti muito com isso [...]. (segunda entrevista).

Mesmo sem querer reconhecer o mérito do trabalho que vem desenvolvendo, o professor entende que tem algo acontecendo e, mais uma vez, reitera o valor do social em meio a isso. Torricelli chama atenção para o fato de que, nessa cidade, as relações sociais, o modo como as pessoas lidam com a educação favorecem o envolvimento dos mais jovens com a escola. Em outro lugar, com outras pessoas, em outras condições, essa história seria outra. Resgatamos, nesse trecho do discurso de Torricelli, ideias que expressam a força do contexto sócio-histórico no desenvolvimento cultural humano, confirmando o que assevera Vigotski (2000) sobre o homem ser "quase social", referindo-se ao fato de que o homem, embora 
tenha uma dimensão biológica, constitui sua natureza pela mediação do sistema de relações sociais constitutivas das práticas sociais das quais toma parte no curso do desenvolvimento da sua vida.

No segundo trecho, Torricelli explica que não reúne as características do que considera um exemplo de professor, pois não se sente possuidor dessas características, entretanto, reconhece que, mesmo não sendo exemplo de profissional, é mediado pelo desejo de fazer algo diferente e todas as suas ações são mobilizadas para isso, para promover mudança no ensino da Matemática. Esse talvez tenha sido o grande diferencial em sua prática. Espinosa (2008), ao esclarecer sobre o que leva o homem a agir, explica-nos que, entre todos os afetos que estão relacionados à mente, à medida que ela age, não há nenhum que não esteja relacionado à alegria ou ao desejo. O desejo é a própria essência do homem, enquanto esta é concebida como determinada a existir, logo, o desejo é o que orienta nosso fazer, nossa ação, nosso juízo sobre as coisas.

Mediado pelo desejo de fazer algo diferente, mas que faça diferença na vida dos alunos, não se deixa seduzir pela prática comum de ir para sala de aula e dar conteúdo sem encontrar um sentido para isso - “Tem que ter sentido... Tem que ter os porquês" - e insiste que os alunos também precisam construir um sentido para estar na escola e estudar Matemática: "Eu sempre insisti que aquilo tinha que ter um valor, um valor... Eu insisti muito com isso [...]. Ou seja, age afetado pelo desejo de promover uma mudança na forma de ensinar (ensinar com um propósito) e na forma de aprender (aprender com propósito).

Espinosa (2008) esclarece que o homem, na sua relação com a realidade, forma ideias mutiladas e confusas ou ideias adequadas, verdadeiras. As ideias mutiladas e confusas originam-se das afecções do corpo, que levam o homem a agir sem, necessariamente, estar ciente das causas. Isto quer dizer que, muitas vezes, o homem é movido por causas externas, causas que não compreende, que desconhece. Nesse caso, o homem é suscetível à diminuição da sua potência de agir, pois, sem compreender o motivo que o leva a agir, a sua situação é de passividade.

Por outro lado, quando na sua relação com a realidade, o homem age tendo consciência do seu ato; quando compreende o que faz e porque faz, diz-se que ele tem ideias adequadas acerca da realidade, nesse caso, ele age, porque só o 
conhecimento verdadeiro leva à ação, à atividade. Nesse caso, ele é causa de si mesmo, isto é, ele sabe o que o afeta de alegria ou de tristeza, por conseguinte, suas ações são mobilizadas no sentido de produzir as condições para manter-se em estado de atividade. No caso de Torricelli, sua relação com a docência é mediada pela ideia de que ensinar significa produzir nos alunos um motivo para aprender.

Compreendemos que Torricelli tem ideias adequadas sobre ensinar e aprender, fato que o ajuda a determinar suas ações e operações. Podemos considerar que o valor atribuído pelo professor ao que faz na sala de aula e o esforço em levar os alunos a também constituírem um valor para a aprendizagem, constitui uma das mediações necessárias para o desenvolvimento de um bom encontro entre professores e alunos, condição essencial para o surgimento de vivências, ou seja, das particularidade que explica a transformação da relação dos alunos com o processo educativo.

Além disso, podemos afirmar, também, com base na narrativa, que as atitudes do professor despertam novas atitudes nos alunos:

Então, daí eu acabei conseguindo pegar aquelas pessoas que entenderam essa ideia antes... Ou que... conseguiram entender essa ideia de que a Matemática precisava se dar esse valor... Então, eu conseguia pegar essas pessoas e estar ainda mais perto delas e aí... A gente começou a montar esses grupos de estudo [...] E que aquilo foi bem bacana... Fazer parte, participar... Mas não acho que só isso, quer dizer... Eu fiz isso, foi um diferencial, uma coisa que não era muito normal de fazer... Que é aquele negócio de dedicar o final de semana, ou o feriado, quer dizer... Eu sempre tive muito prazer, sempre gostei de fazer isso, de combinar pra estudar alguma coisa... Isso com alunos... Estes alunos eram fortes aliados na escola para valorizar mais a Matemática... Para outros também perceber como ela tem esse valor. Então, eu corria muito atrás disso. Eu comparo muito isso como uma escolinha de futebol. Como se fosse um professor ou um treinador... De um time... Que aquele time ou aquela escolinha tem que existir na cidade, porque tem que ter na cidade um lugar para os alunos daquela escolinha se exercitar... E eu quis mais do que isso... Por exemplo... Eu quis que dali saísse talentos... É como se fosse... Eu me esforcei para que dali saísse talentos... Para que a gente fosse reconhecido por isso também... E isso aconteceu quando os alunos começaram a sair dessa realidade, eles foram dando para gente todo um respaldo de ter ficado por aqui estudando essa Matemática e tal [...]. (segunda entrevista). 
Pela narrativa, compreendemos que a atitude do professor no desenvolvimento da atividade de ensino afetou os discentes de forma positiva. A valorização da Matemática foi muito importante, mas o fato de dedicar os finais de semana, feriados, organizar grupos de estudo são atitudes que revelam a disponibilidade do professor, o sentimento de responsabilidade em relação aos alunos, ou seja, modos de ser professor traduzido no esforço de produzir uma atividade capaz de transformar a realidade dos alunos.

Pelo discurso do professor, compreendemos que os alunos foram afetados por essas atitudes do docente e, também, pelo exemplo de outros alunos que vinham se destacando na escola e na comunidade em função dos resultados das Olimpíadas de Matemática. Afetados de forma positiva, os alunos passaram a compartilhar dos mesmos interesses que o professor, a vislumbrar as mesmas possibilidades, indicando que a relação com os estudos deixou de ser sentida como obrigação, passando a ser mediada pelo desejo de aprender, configurando-se, assim, uma transformação na condição afetiva dos alunos. Essa transformação no modo de se relacionar com os estudos em Matemática é o que mostra que a consciência de cada um está se transformando, pois, estudar Matemática deixa de ser sentido e vivido como obrigação, e passa a ser sentido e vivido como satisfação. Essa transformação evidencia a ocorrência de vivências.

A afetação produzida nos alunos por meio dessas mediações contribuiu para a constituição da prática educativa bem-sucedida, que vem se configurando na escola e que vem sendo reconhecida em toda a cidade e, também, no estado. A escola vem sendo reconhecida nacionalmente pelo destaque nos resultados que os alunos apresentam, tanto no Exame Nacional do Ensino Médio (ENEM), desde de 2011, como pelas premiações alcançadas pelos alunos e pelas alunas nas Olimpíadas de Matemática, Língua Portuguesa e Química.

Essa realidade objetiva indica que ocorreu transformação na relação dos alunos com a atividade de estudo. Há, claramente, a constituição de novas conexões com o meio (situação social vivida na escola, na sala de aula, nas disciplinas escolares), confirmando a tese de que “[...] a essência do desenvolvimento psicológico não se baseia aqui no desenvolvimento posterior, mas na mudança de 
conexões" (VIGOTSKI, 2004, p. 117). São as mudanças de conexões que atestam a produção de vivências capazes de transformar a consciência dos estudantes.

Essa compreensão expande nossa tese de pesquisa de que o professor consegue realizar prática educativa bem-sucedida quando afeta e é afetado positivamente por seus alunos. Os alunos, por sua vez, ao serem afetados positivamente, criam relação de sentido que potencializam o desejo por continuar aprendendo e se desenvolvendo. Expandir nossa tese foi possível com base na compreensão do que significa vivência, que encontra ressonância na ideia espinosana de que "[...] o corpo humano é tanto mais forte, mais potente, mais apto à conservação, à regeneração, à transformação, quanto mais ricas e complexas forem suas relações com outros corpos." (CHAUI, 2011, p. 73).

Continuando na busca por zonas de sentido que revelem como a prática educativa desenvolvida por Torricelli se constituiu bem-sucedida, continuamos apreendendo as significações produzidas pelo professor acerca de como ele se sente diante do trabalho que realiza:

Essa conquista é fundamental para o nosso trabalho de hoje [...] a principal coisa é que esse fato nos ajuda bastante para que a gente consiga continuar nesse processo [...] Que as coisas estão acontecendo muito bonito por aqui... Então, ter esses alunos, ter essas aprovações é fundamental para que esse processo continue, para que os alunos sejam interessados ainda [...]. (entrevista reflexiva).

O nosso sentimento é um sentimento muito bom... Assim... Um sentimento de... Uma conquista... Uma excelente sensação [...] Porque nós somos profissionais, mas nós não tivemos as chances que esses meninos tiveram, mesmo assim nós conseguimos [...]. (entrevista reflexiva).

De modo a injetar em cada um de nós uma energia que faz com que continuemos assim numa luta [...]. (entrevista reflexiva)

Porque sempre que a gente encontra professores deles por aí, a gente escuta que eles são excelentes alunos [...]. Então, isso é uma demonstração de que nós estamos fazendo um bom trabalho aqui... Essa mudança que está acontecendo aqui deixa a gente muito satisfeito. É uma das melhores coisas que pode acontecer para nós. [...]. (entrevista reflexiva).

Embora o professor não se veja como bem-sucedido e nem admita que realiza prática educativa bem-sucedida, os trechos do discurso expõem afetos que revelam, mais uma vez, estado de satisfação traduzido em orgulho, realização profissional, valorização, autoestima, enfim, estados afetivos que denotam o quanto essa 
situação social contribui para que o professor tenha sua potência de agir aumentada, o que reitera a ideia de que o sucesso das práticas educativas produz um estado afetivo no professor que contribui com a sua "[...] verdadeira satisfação de ânimo [...]”, o que, para Espinosa (2008, p. 207) representa o aperfeiçoamento da razão (afeto e cognição), a satisfação consigo mesmo e que o professor tende a preservar, porque "[...] o homem afetado de alegria nada mais deseja do que conservá-la, com um desejo tanto maior, quanto maior for a alegria”.

Por consequência, mediado pelo afeto de satisfação, a luta de Torricelli é para conservar seu estado. $\mathrm{O}$ afeto de alegria aumenta a potência humana, ou seja, aumenta a capacidade de agir e pensar, o que, no caso do professor, o torna cada vez mais atuante junto aos alunos. A sua atividade consiste em garantir que os alunos também tenham sucesso, porque o sucesso dos alunos é o seu sucesso, a garantia do reconhecimento do trabalho, logo, a garantia da satisfação. Isso tudo acontece porque, segundo Espinosa (2008, p. 325), "[...] a satisfação consigo mesmo é, na realidade, a maior coisa que podemos esperar".

Para conservar esse estado afetivo, professores e alunos se esforçam no sentido de continuar envolvidos em tais atividades. Continuar envolvidos pode ser considerada também condição necessária para que, na escola, mais professores e alunos consigam realizar práticas educativas bem-sucedidas, ou seja, é preciso produzir situações que elevam o nível de satisfação de professores e alunos na escola. Afetados de alegria, professores e alunos transformam sua relação com a educação, produzem vivências que favorecem a força ativa da mente, necessária aos processos de ensino e aprendizagem, porque a alegria, e todos os afetos dela derivados, é o sentimento responsável pelo aumento da força para existir.

As discussões aqui sistematizadas partiram da análise dos significados e sentidos produzidos pelo professor sobre a prática educativa com o objetivo de apreender os afetos mobilizados nessas relações e as vivências que as afetações produzidas nessas situações promovem na vida do professor e, consequentemente, dos alunos. Apreendemos, dessas significações, as zonas de sentido que nos aproximassem das ideias constituídas por Torricelli sobre a educação escolar, sobre ser professor e sobre o processo de ensino e aprendizagem. Ao interpretar as significações produzidas pelo docente, entendemos que, mediado por ideias 
adequadas, o professor tem conseguido organizar situações sociais que se revestem de práticas educativas consideradas bem-sucedidas no sentido de alcançar o objetivo de levar seus alunos ao desenvolvimento de suas potencialidades.

As práticas educativas que o professor tem conseguido planejar e sistematizar se transformam em oportunidades, nas quais as ações concretas se voltam para promover mudanças na forma de ensinar (ensinar com um propósito) e na forma de aprender (aprender com propósito). Não se trata de ensinar apenas conteúdos, mas de possibilitar o desenvolvimento de si e dos outros. Confirma-se, então, a máxima de Vigotski de que:

Todo bom ensino que se desenvolve por meio de práticas educativas é aquele que gera aprendizagem e colabora com o desenvolvimento de funções psíquicas superiores, ou seja, colabora com o desenvolvimento do pensamento, linguagem, memória, atenção dirigida, formação de conceitos, consciência, entre muitas outras funções que nos tornam qualitativamente diferentes dos outros animais. Portanto, prática educativa bem-sucedida é aquela que contribui para que os alunos se tornem mais humanos do ponto de vista sócio-histórico. (MARQUES; CARVALHO, 2017, p. 3).

Além de contribuir com o desenvolvimento de seus alunos do ponto de vista humano, essa pesquisa mostrou que Torricelli desenvolve sua prática para atender a duas funções da educação escolar, que, embora pareçam antagônicas, constituem unidade de contrários. A mesma educação escolar que, em princípio, serve ao atendimento das necessidades mais imediatas dos alunos, transforma-se em prática social transformadora, porque altera a realidade social. Mediado por essa ideia, defende que a docência não pode ser realizada de qualquer forma; ao contrário, necessita de porquês, de sentido, de intencionalidade e de sistematização. A fim de concretizar esse ideal, o professor assume a responsabilidade pedagógica e social da atividade que realiza junto aos discentes.

A subjetivação da realidade objetiva levou Torricelli a produzir prática educativa singular que, embora não a reconheça como bem-sucedida, produz nele estado de satisfação de ânimo responsável pelo aumento da sua potência de agir. A fim de manter esse estado de satisfação, o professor se esforça pelo sucesso dos alunos e organiza suas aulas com situações sociais capazes de mediar a 
transformação dos alunos, pois estes têm conseguido produzir novos sentidos para estar na escola e aprender, têm estabelecido novas conexões e vislumbrado novas expectativas para a vida futura. Essa nova realidade é a comprovação de que está acontecendo algo novo, algo particular e peculiar que altera a relação social. Essa particularidade, o algo novo é, segundo Vigotski, o principal indicativo da existência de vivências, pois elas se manifestam nas peculiaridades, naquilo que é particular das situações sociais, e mesmo sendo a unidade da relação afetointelecto, “[...] não seria correto encará-las como manifestação exclusiva da esfera emocional” (JEREBTSOV, 2014, p. 16).

\section{Considerações finais}

O objetivo deste artigo foi analisar a categoria vivência e sua relação com as práticas educativas escolares. Essa discussão, fundamentada nas ideias de Vigotski, Espinosa e apropriadores, favorece a compreensão de que no desenvolvimento do psiquismo humano os estados afetivos assumem a condição de fenômenos éticos, propulsores ou inibidores da autonomia. Os afetos são vistos como inerentes à condição humana e, por consequência, a fonte de explicação de muitas condutas, regulador interno de nosso comportamento, tendo sua gênese no social, pela mediação das significações.

As significações constituídas em atividade expressam o modo como compreendemos as coisas, mas também como a sentimos. É o resultado da internalização do social que nos afeta e se converte em individual, expressão da nossa consciência, da nossa subjetividade, em síntese, é o resultado de vivências.

A discussão envolvendo vivências exige compreensão da realidade como produto da dialética condições objetivas e subjetivas. No escopo das condições objetivas estão aquelas ligadas à realidade material, concreta, sem a qual toda e qualquer atividade humana tem a sua qualidade comprometida. $\mathrm{Na}$ escola, isso se reflete na estrutura física das salas de aula, dos laboratórios; no material didático e tecnológico disponível; nas condições de trabalho; nas políticas salariais; nas políticas de formação continuada; na estrutura econômica, social, cultural e política da sociedade que se materializa por meio dos currículos escolares; etc. 
As condições subjetivas se constituem dos modos de ser (pensar, sentir e agir) dos sujeitos que vivem e se constituem na mediação com a realidade objetiva. Elas expressam o modo como os seres humanos significam a realidade, logo, são a expressão das subjetividades humanas. Trazendo para a educação, as condições subjetivas se revelam no modo de ser de professores e alunos, isto é, nas suas motivações, nas suas expectativas, no modo como vivem os processos educativos e como significam a realidade na qual atuam e na sociedade na qual vivem.

Desse modo e considerando essas condições, reconhecemos na categoria vivência o valor de poder trazer muitas contribuições ao campo da produção de conhecimento em Educação, sobretudo às pesquisas que buscam compreender como cada pessoa (professores e alunos) é afetada na sua relação com o mundo, quais os afetos produzidos nessa relação - alegres e tristes - e como se constitui o encontro alegre na sala de aula, na escola. Tal análise, entretanto, não se produz de forma simples, pois requer o entendimento de como a pessoa toma consciência do meio e o concebe (adequadamente ou inadequadamente), de como ela se relaciona afetivamente com certos acontecimentos e de como esse relacionamento afetivo com o meio (re)orienta a produção de sentidos que são produzidos sobre o mundo que a constitui e que é constituído por ela. Enfim, são possibilidades de pesquisas que têm o potencial de continuar explicando aquilo que Vigotski buscou elucidar na sua curta passagem por esta vida: como nos tornamos humanos. 


\section{Referências}

AGUIAR, W. M. J. de; OZELLA, S. Apreensão dos sentidos: aprimorando a proposta dos núcleos de significação. Rev. Bras. Estud. Pedagog., Brasília, v. 94, n. 236, p. 299-322, Apr. 2013. Available from <http://www.scielo.br/scielo.php?script=sci_arttext\&pid=S2176-

66812013000100015\&lng=en\&nrm=iso>. access on 14 Julh 2019.

BARTUSCHAT, W. Espinosa. Porto Alegre: Artmed, 2010. p. 64-79.

CHAUI, M. Desejo, paixão e ação na Ética de Espinosa. São Paulo: Companhia das letras, 2011.

DELARI JUNIOR, A. Vigotski: consciência, linguagem e subjetividade. Campinas, SP: Alínea Editora, 2013. p. 16-34.

ESPINOSA, B. de. Ética. Belo Horizonte: Autêntica Editora, 2008.

ESPINOSA, B. de. Tratado da reforma do entendimento. São Paulo: Editora Escala, 2007.

JEREBTSOV, S. Gomel - A cidade de L. S. Vogotski: pesquisas científicas contemporâneas sobre instrução no âmbito da teoria histórico cultural de L. S. Vigotski. In: Veresk - cadernos acadêmicos internacionais. Estudos sobre a perspectiva histórico-cultural de Vigotski - Brasília, UniCEUB, 2014. p. 7-28.

MARQUES, E. de. S. A; CARVALHO, M. V. C. de. Prática educativa bem-sucedida na escola: reflexões com base em L. S. Vigotski e Baruch de Espinosa. Rev. Bras. Educ., Rio de Janeiro, v. 22, n. 71, e227169, 2017. Disponível em: http://www.scielo.br/scielo.php?script=sci_arttext\&pid=S1413-

24782017000400221\&lng=en\&nrm=iso. Acesso em: 12 jul. 2019.

MARQUES, E. de. S. A; CARVALHO, M. V. C. de. Vivência e afetação na sala de aula: um diálogo entre Vigotski e Espinosa. Revista da FAEEBA - Educação e Contemporaneidade, Salvador, v. 23, n. 41, p. 41-50, jan./jun. 2014. Disponível em: https://www.revistas.uneb.br/index.php/faeeba/article/view/822/580. Acesso em: 12 jul. 2019.

MARQUES, E. de S. A. O sócio-afetivo mediando a constituição de práticas educativas bem sucedidas na escola. 2014, 324 p. Doutorado (Tese em Educação) Universidade Federal do Piauí. Piauí: Teresina, 2014.

MARX, K. Grundrisse: manuscritos econômicos de 1857-1858: esboços da crítica da economia política. São Paulo: Boitempo Editorial, 2011. p. 39-64.

PRESTES, Z. Quando não é quase a mesma coisa: traduções de Lev Semionovitch Vigotski no Brasil. Campinas, São Paulo: Editora Autores Associados, 2012. 
SAVIANI, D. Pedagogia histórico-crítica: primeiras aproximações. Campinas, São Paulo: Autores Associados, 1997.

TOASSA, G. Emoções e vivências em Vigotski. Campinas, SP: Papirus, 2011.

TOASSA, G.; SOUZA, M. P. R. de. As vivências: questões de tradução, sentidos e fontes epistemológicas no legado de Vigotski. Psicol. USP, São Paulo, v. 21, n. 4, 2010.

VIGOTSKI, L. S. Manuscritos de 1929. Edu. Soc. [on line], 2000, v. 21, n 71, PP. 21-44.

VIGOTSKI, L. S. Pensamento e linguagem. São Paulo: Martins Fontes, 1998.

VIGOTSKI, L. S. Psicologia pedagógica: edição comentada. São Paulo: Martins Fontes, 2010.

VIGOTSKI, L. S. Sete aulas de Vigotski sobre os fundamentos da Pedologia. Organização e tradução: Zoia Prestes e Elizabeh Tunes. Rio de Janeiro: E-papers, 2018.

VIGOTSKI, L. S. Teoria e método em psicologia. São Paulo: Martins Fontes, 2004.

VIGOTSKI, L. S. Quarta aula: a questão do meio na pedologia. Tradução de Márcia Pileggi Vinha. Psicol. USP. São Paulo, v. 21, n. 4, 2010. Disponível em: http://www.scielo.br/scielo.php?script=sci_arttext\&pid=S0103-

65642010000400003\&lng=pt\&nrm=iso. Acesso em: 12 jul. 2012 . http://dx.doi.org/10.1590/S0103-65642010000400003.

VIGOTSKI, L. S. A construção do pensamento e da linguagem. São Paulo: Martins Fontes, 2009. 